\title{
Projected change in heat waves over China using the PRECIS climate model
}

\author{
Honglong Yang ${ }^{1,2}$, Yinlong $\mathrm{Xu}^{2, *}$, Lei Zhang ${ }^{1}$, Jie $\mathrm{Pan}^{2}{ }^{2} \mathrm{Xia} \mathrm{Li}^{1}$ \\ ${ }^{1}$ College of Atmospheric Sciences, Lanzhou University, Lanzhou 730000, China \\ ${ }^{2}$ Institute of Environment and Sustainable Development in Agriculture, Chinese Academy of Agricultural Sciences, \\ Beijing 100081, China
}

\begin{abstract}
An analysis of the simulated distribution of present (1961-1990) and future (2071-2100) heat waves in China from one run of a regional model (PRECIS) using the IPCC Special Report on Emissions Scenarios A2 scenario is presented. Results indicate that PRECIS simulates the spatial distribution of the extreme high tail of the probability density function of summer temperature in the present case compared to observations. In addition, the characterization of anticyclonic circulation anomalies with heat waves is well simulated by the model. The model projects that heat waves will be more intense, longer and more frequent, with distinct geographical patterns. Western northwest China and northeast China are projected to experience more heat waves than at present.
\end{abstract}

KEY WORDS: PRECIS · SRES A2 · Heat waves

\section{INTRODUCTION}

Anthropogenic effects have already significantly influenced global and regional climate; it is estimated that the global mean surface temperature has risen by $0.74 \pm 0.18^{\circ} \mathrm{C}$ over the last $100 \mathrm{yr}(1906-2005)$ (IPCC 2007). This rise in mean temperature has probably resulted in changes in extreme climate events, which would substantially affect human society, ecosystems and the environment. The type, frequency and intensity of extreme events are expected to change as the Earth's climate changes, and these changes could occur even with a relatively small mean climate change. Recently, a number of studies have reported a reduction in the frequency of extreme low monthly and seasonal average temperatures but a slight increase in that of extreme high average temperatures worldwide (Alexander et al. 2006, Caesar et al. 2006). Changes in some extreme events have already been observed (IPCC 2007), such as increases in the frequency and intensity of heat wave events. Several recent studies have explicitly discussed possible future changes in heat waves, and found a higher risk of more intense, longer-lasting and more frequent heat waves in the future (Meehl \& Tebaldi 2004, Schär \& Jendritzky 2004, Clark et al. 2006). Beniston (2004), Schär et al. (2004) and Stott et al. (2004) used the European 2003 heat wave to illustrate the types of heat waves that are likely to become more common in a warmer future climate. A multi-model ensemble has shown that heat waves are simulated to increase over the latter part of the 20th century, and are projected to increase in many regions (Tebaldi et al. 2006).

In China, mean surface temperatures have risen by $0.79^{\circ} \mathrm{C}$ over the last $100 \mathrm{yr}$ (Ren et al. 2003). The relatively small increase in mean climate has altered the tails of the temperature distributions. The occurrence of cold extremes have been decreasing and that of warm extremes increasing during recent decades (Yan et al. 2002), but the number of hot days (maximum temperature over $35^{\circ} \mathrm{C}$ ) was found to display a slightly decreasing trend (Zhai \& Pan 2003), which may be due to urbanization (the relocation of observation stations from cities to villages). Xu et al. (2006a,b) used a regional climate model to simulate mean cli- 
mate in response to enhanced greenhouse gas concentration and found that there would be a more marked surface air temperature increase in the north of China relative to the south. The increase in temperature may change the distributions of minimum and maximum temperatures, leading to a reduction in the diurnal temperature range (Zhang et al. 2007). Zhang et al. (2006) used extreme climate indices to analyze extreme events and found that hot events are more frequent in China, consistent with the finding of Gao et al. (2002). A greater number of warm extremes imply an increased frequency of heat waves in China, with severe implications for society, the economy and the environment. For instance, heat waves have had a notable impact in Europe, such as the deaths of thousands of elderly people, the destruction of large areas of forest by fire and adverse effects on water ecosystems and glaciers (Gruber et al. 2004, Kovats et al. 2004, Schär \& Jendritzky 2004, Kovats \& Koppe 2005). Estimates based on the statistical excess over mean mortality rates amounted to between 22000 and 35000 heat-related deaths across Europe as a whole in the 2003 heat waves (Valleron \& Boumendil 2004). Reducing the impacts of future heat waves requires addressing fundamental questions, such as the potential impact of such extreme heat events in the past and the frequency of their occurrence in the future.

The present study focuses on the analyses of two 30 yr simulations. The first examines the time period 1961-1990 (present) and the second the period 20712100 (future) under the IPCC Special Report on Emissions Scenarios (SRES) A2 scenario using PRECIS (Providing Regional Climates for Impacts Studies) (Jones et al. 2004). The analysis provides an opportunity to examine the behavior of the PRECIS model in simulating extreme high temperature events (heat waves) and to make comparisons with observations. Simultaneously, we investigated future heat waves in China by using the IPCC SRES A2 scenario so as to make better use of simulation results for impact studies.

\section{MODELS, DATA AND METHODS}

To simulate fine-scale climate change scenarios, the regional model system PRECIS developed by the Hadley Centre, which provides regional climate information, was used with a relatively high horizontal resolution $\left(0.44^{\circ}\right.$ latitude by $0.44^{\circ}$ longitude in rotation coordinates) and 19 vertical levels under forcing from the IPCC SRES A2 scenario. The lateral boundary conditions for PRECIS were obtained from a global atmosphere general circulation model (GCM), HadAM3P, which employs a spatial resolution of $1.25^{\circ}$ latitude by $1.875^{\circ}$ longitude. The sea-surface boundary conditions derived from recent observations were combined with the observations of changes in the coupled oceanatmosphere HadCM3 GCM (see Jones et al. 2004, Rowell 2005 for details).

The PRECIS system was introduced to China by the Met Office Hadley Centre in 2003, to develop the highresolution $(50 \times 50 \mathrm{~km})$ SRES climate change scenarios over China. These scenario data sets have been applied in assessing the impacts of climate change on Chinese agriculture (Lin et al. 2005). The PRECIS model domain over China uses $145 \times 112$ grid points (longitude $\times$ latitude) (Fig. 1). PRECIS can simulate the distribution pattern of maximum and minimum surface air temperatures over China, but the simulated topographic precipitation tends to be higher than observed values, which is caused by stronger vertical ascent due to the dynamic effects of the higher resolution (Zhang et al. 2006).

We completed two 30 yr simulations using one run of PRECIS under the A2 scenario, thus representing the current climate for the period 1961-1990 and the future greenhouse-gas climate for the period 20712100. We compared the model results against a $0.5^{\circ} \times$ $0.5^{\circ}$ daily temperature data set over China for the $30 \mathrm{yr}$ period of 1961-1990 (hereafter referred to as CN05), developed by $\mathrm{Xu}$ et al. (2009). The data set was constructed by interpolating observations from 751 stations distributed throughout the entire Chinese territory except Taiwan. The same interpolation was used in generating the Climatic Research Unit (CRU, University of East Anglia, Norwich, UK) data set, whereby a gridded climatology is calculated first and then a gridded anomaly is added to it to obtain the final data. The CN05 is interpolated into corresponding model grids using the bilinear method with topography

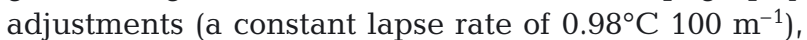
due to the different spatial resolution and topography between CN05 and the simulation.

To analyze if heat waves will change in the future, a definition of a heat wave is required. Many definitions could be applied to heat waves to quantify duration and/or intensity (Karl \& Knight 1997, Huth et al. 2000, Palecki et al. 2001). We chose to define a heat wave on the basis of the concept of exceeding specific thresholds, and thus analyze heat wave duration and frequency. The extreme temperature thresholds (ETTs) are determined according to simulated summer and autumn (June-November) daily maximum temperatures. Considering one grid point as an example, the method is described as follows. Firstly, the daily maximum temperatures for a particular calendar day (centered on a 5 d window; Zhang et al. 2005) for the period 1961-1990 are sorted into ascending order. For example, to estimate the threshold for 13 January, the $5 \mathrm{~d}$ window selects data for all days in the base period 


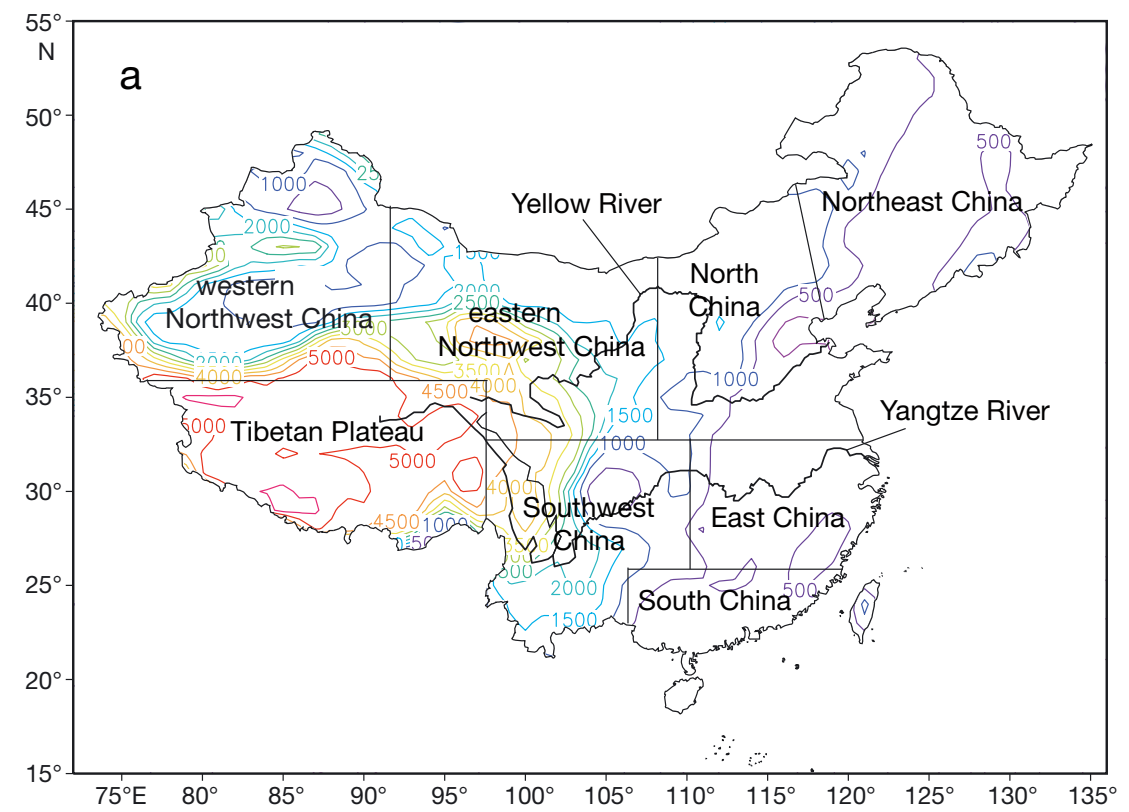

b

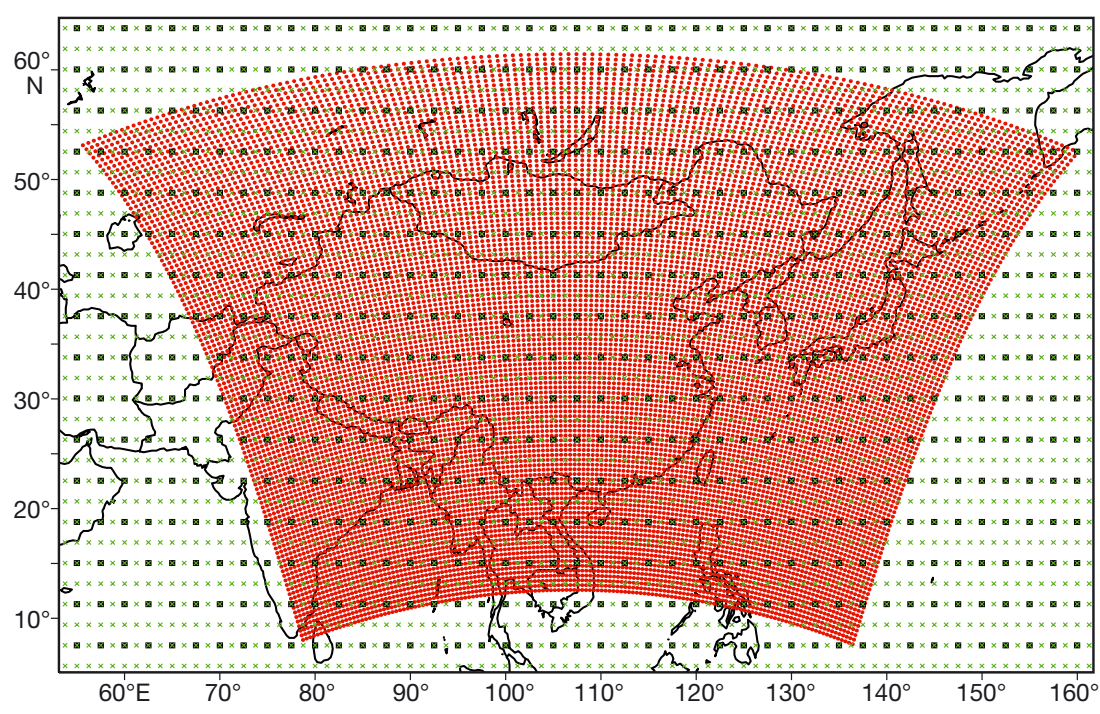

Fig. 1. Topography of the study area. (a) The 8 study regions and the simulated topography (colour contours) in China. The Yellow and the Yangtze Rivers are labeled. (b) PRECIS domain over China. Grid size: $145 \times 112$; (×) HadCM3 grids; $(\bullet)$ HadAM3P grids; $(\bullet)$ PRECIS grids

dated 11-15 January. Secondly, we calculated the 90th percentile of the daily maximum temperature series (183 maximum temperature thresholds were obtained). Finally, we selected the maximum of these calendar-day 90th percentiles as the ETTs. Bonsal's method was adopted for determining the thresholds of extreme events (Bonsal et al. 2001). If a meteorological element has $n$ values, these values will be sorted in ascending order, $x_{1}, x_{2}, \ldots, x_{m}, \ldots x_{n}$ and the probability of an element not exceeding $x_{m}$ is:

$$
\mathrm{p}=(m-0.31) /(n+0.38)
$$

where $m$ is a serial number of $x_{m}$ and $n$ is the total number of meteorological elements. If there are 30 values, the 90th percentile is interpolated linearly between $x_{27}(p=87.9 \%)$ and $x_{28}(p=$ $91.1 \%)$. Once ETTs are calculated for each grid point, the numbers of heat waves in each grid point are counted. A heat wave is defined as a period of at least 5 consecutive days with daily maximum temperatures above ETT; heat wave frequency is the number of heat waves occurring in a given time interval; and heat wave duration is the average duration (d) that the heat waves last.

In order to better represent the spatial distribution of climate change, 8 regions in China were considered (see Fig. 1). The simulated topography is also shown in Fig. 1.

\section{RESULTS}

\subsection{Ability of PRECIS to simulate heat waves}

PRECIS has been used to simulate mean and extreme climate events in China. According to Xu et al. (2006a,b) PRECIS can effectively simulate the distribution characteristics of surface air temperatures over China. However, simulated precipitation is greater than observed along the mountainous belts over the eastern edge of the Tibetan Plateau, because the parameterization of physical precipitation processes in the model is too sensitive to topography. Zhang et al. (2006) indicate that PRECIS can simulate well the distribution characteristics of extreme events.

To further demonstrate the ability of the PRECIS model to simulate extreme climate events in China, we also analyzed the simulated extreme high tail of the probability density function of temperature and circulation patterns in the case of heat waves.

Fig. 2 shows the observed and simulated presentday spatial distribution of ETTs in China. Present-day ETTs range from 10 to $35^{\circ} \mathrm{C}$, with the highest values in western Northwest China and East China, intermediate values in North and Northeast China, and the low- 

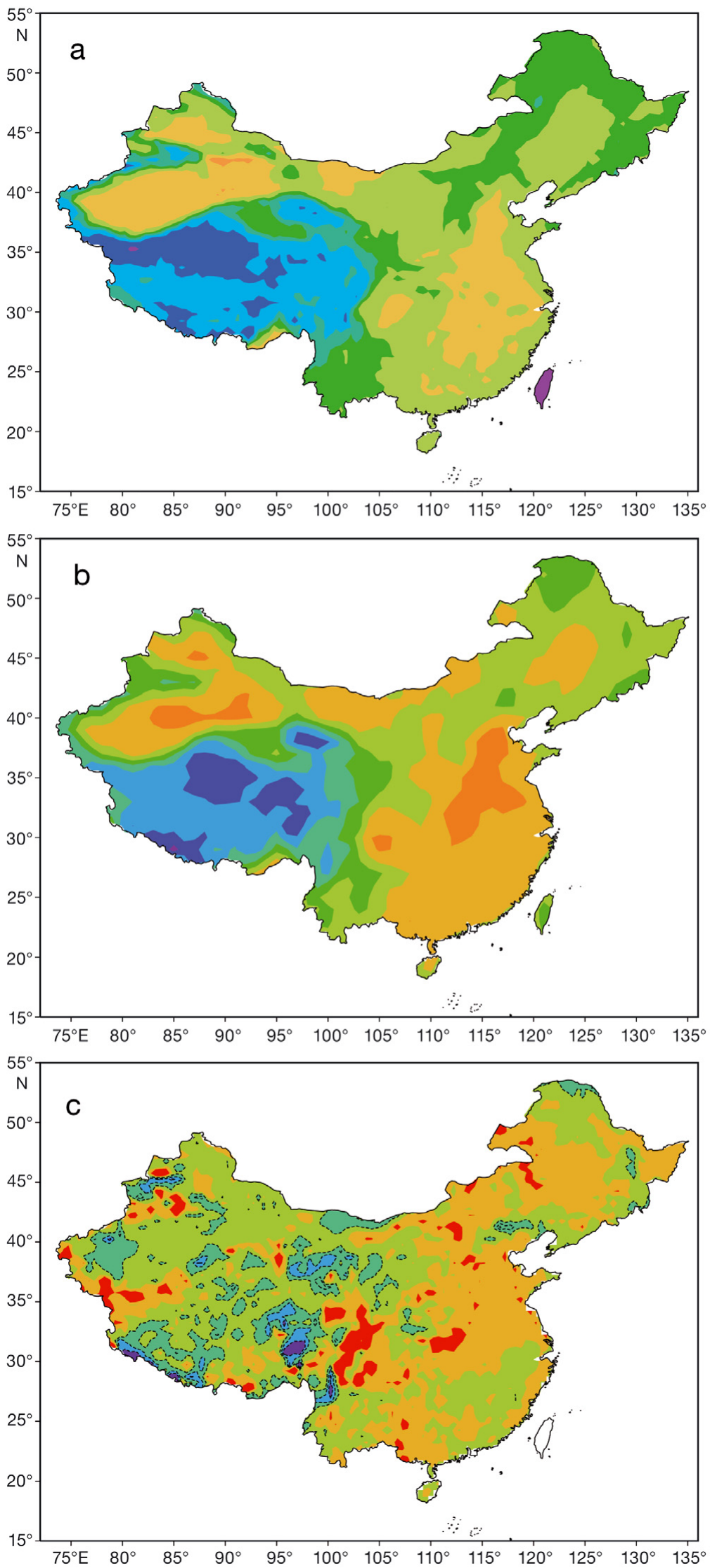

est values on the Tibetan Plateau (Fig. 2a,b). The simulated ETT pattern matches well with the observations (Fig. 2a,b), but is sometimes slightly higher, especially in North, East, Southwest and Northeast China, with a warm bias of about $3^{\circ} \mathrm{C}$ (Fig. 2c). The simulated warm bias may be caused by the simulated warmer maximum temperature. In general, the simulation shows similar spatial patterns to the observations.

In order that climate models correctly simulate the probability of extreme hot days, the correct simulation of the probability of the occurrence of blocking is crucial. Heat waves are generally associated with specific atmospheric circulation patterns represented by semi-stationary $500 \mathrm{hPa}$ positive height anomalies that dynamically produce subsidence, clear skies, light winds, warm-air advection and prolonged hot conditions at the surface (Kunkel et al. 1996, Palecki et al. 2001, Xoplaki et al. 2003, Meehl \& Tebaldi 2004, Fischer et al. 2007). Take Wuhan as an example, where the PRECIS model was used to simulate $500 \mathrm{hPa}$ positive height anomalies. Based on National Centers for Environmental Prediction (NCEP) reanalysis and the threshold definition of a heat wave in the present study, height anomalies at $500 \mathrm{hPa}(\mathrm{gpm})$ for Wuhan heat waves over the period 1961-1990 (Fig. 3a) are positive, at +50 gpm over North China. A stratification based on composite present-day heat waves from the model for Wuhan over the period of 1961-1990 (Fig. 3b) shows comparable amplitudes and patterns, with positive $500 \mathrm{hPa}$ height anomalies of $+45 \mathrm{gpm}$. There is also an amplification of the positive $500 \mathrm{hPa}$ height anomalies associated with a given heat wave for Wuhan in the future climate

Fig. 2. Spatial distribution of extreme temperature thresholds $\left(\mathrm{ETTs},{ }^{\circ} \mathrm{C}\right)$ for the present-day climate: (a) observed ETTs from CN05, (b) simulated ETTs and (c) differences between observations and simulation 

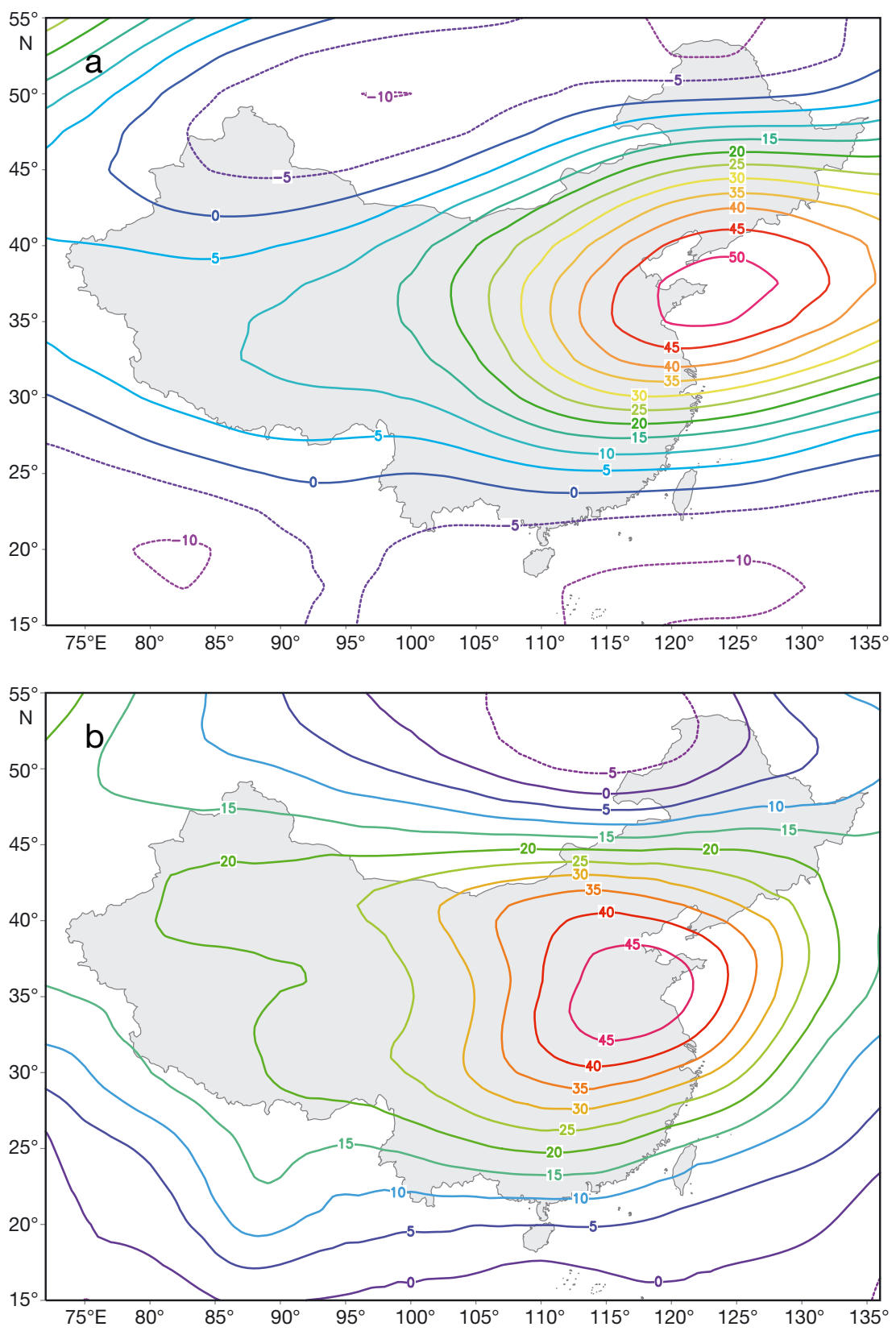

Fig. 3. Height anomalies at $500 \mathrm{hPa}(\mathrm{gpm})$ during heat waves. (a) Wuhan heat waves during the period 1961-1990 from NCEP reanalysis data. (b) Simulated heat waves in the present-day climate (1961-1990), computed at grid points near Wuhan. In both cases, the base period is summer and spring (June-November) tions well (0.30 versus 0.33 occurrences per year). In general, the model can capture the anticyclonic circulation anomalies during the heat waves, which proves the model can reliably simulate heat waves.

\subsection{Changes in heat indices}

\subsubsection{Heat wave frequency}

At present, heat waves occur most frequently in Southwest and western Northwest China and least frequently in East, North and South China (Fig. 4a). In the future, heat waves as simulated by one run of PRECIS under the SRES A2 scenario show a distinct geographical pattern (Fig. 4b). As the climate responds to an increase in greenhouse gas concentration, the simulated change in heat wave frequency is positive in all areas of China, which reflects an increasing trend in heat waves throughout China in the future. In the present study, we found that the number of heat waves in China increases most markedly in Southwest, South and Northeast China and on the Tibetan Plateau, which all show positive anomalies $>5$ heat waves per year. Thus the areas most susceptible to heat waves in the present climate (greatest values in Fig. 4a) would experience the greatest increase in heat wave occurrence in the future. However, the impact of increased heat wave occurrence may be more serious in other areas that are currently less susceptible, such as East, Northeast and North China, because these areas might not be well adapted to heat waves in the 21st century. (data not shown), while the present-day anomaly is larger by about $5 \mathrm{gpm}$ in the model, which predicts more severe heat waves in the future. The simulated $500 \mathrm{hPa}$ height anomaly is relatively weaker and further north, because the simulated subtropical high is weaker in the West Pacific in summer (Xu et al. 2006b). Meanwhile, the simulated frequency of blocking (positive $500 \mathrm{hPa}$ height anomalies) matches the observa-

\subsubsection{Heat wave duration}

The simulated spatial distribution of heat wave duration is projected in Fig. 5a,b. The present-day average duration of heat waves ranges from 5 to $10 \mathrm{~d}$, with most regions below $7 \mathrm{~d}$, whereas for future climate, the range shifts from 7 to $14 \mathrm{~d}$, with most regions over $9 \mathrm{~d}$. Thus there is a shift towards longer heat wave dura- 

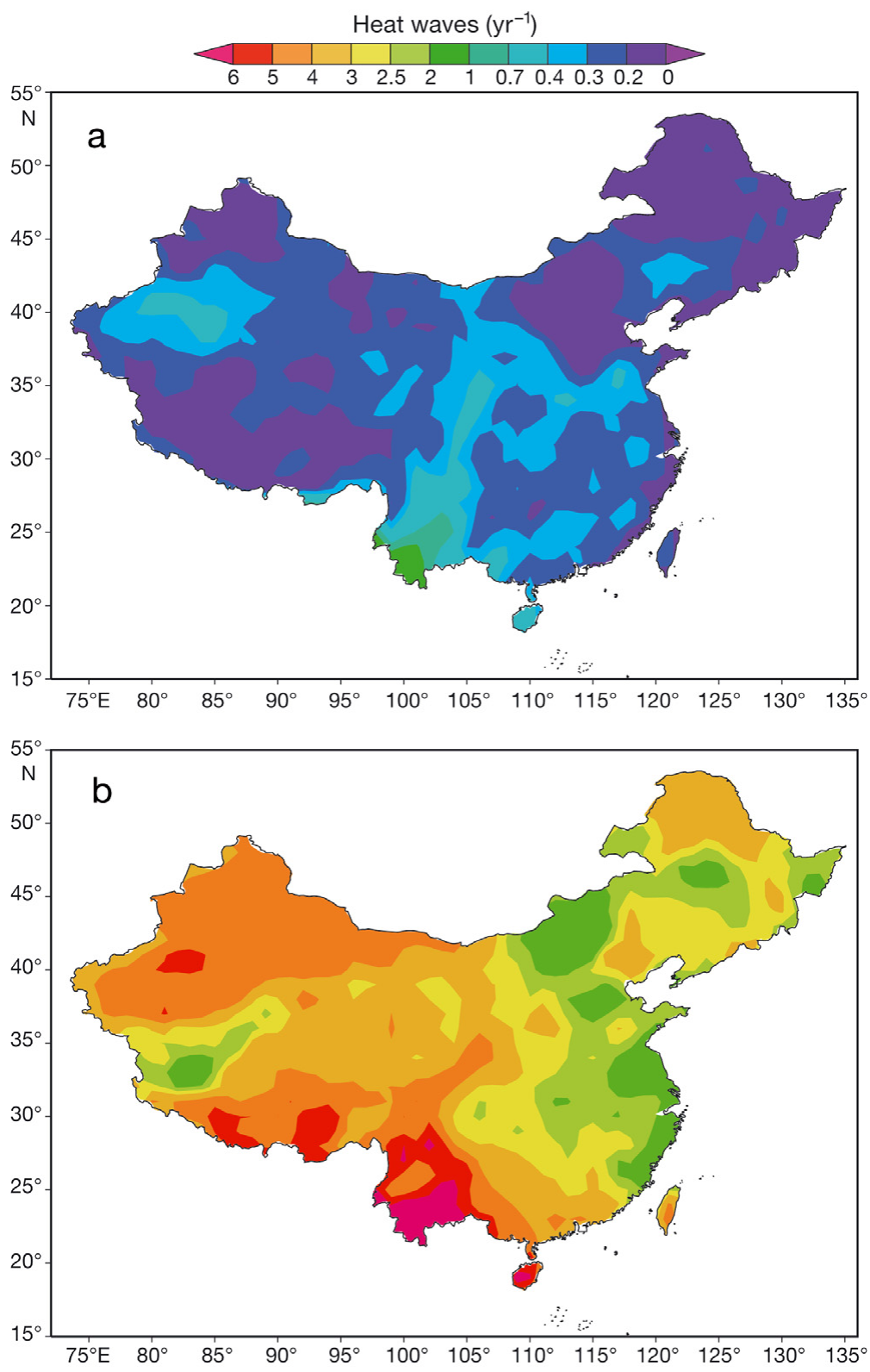

Fig. 4. Simulated spatial distribution of the number of heat waves per year for (a) present (1961-1990) and (b) future (2071-2100) climate

tion, as the average duration increases from 6.7 to $9.2 \mathrm{~d}$. In the present study, the longest durations are projected in western Northwest China, where the number of present-day heat waves ranges from 5 to 8 heat waves per year, rising to 9 to $14 \mathrm{~d}$ in the future, representing an increase of over $200 \%$ in mean heat wave occurrence.

There is a corresponding increase in the average maximum temperature (AMT) during the heat waves (Fig. 6a). Over a wide area, the AMT is exceeded by $\sim 1.2^{\circ} \mathrm{C}$ in 1961-1990. In future, the AMT of China is predicted to be over $35^{\circ} \mathrm{C}$ (threshold for the definition of a hot day in China), with the exception of the
Tibetan Plateau and part of Northeast China, where peaks of the maximum temperature distribution in western Northwest China and East China could reach an AMT of over $45^{\circ} \mathrm{C}$.

\section{DISCUSSION}

Heat waves can be represented by a variety of indices such as intensity, duration and frequency. A heat wave index based on the concept of exceeding specific thresholds was adopted in the persent study to provide a spatial representation of heat wave climatology via simulation. The climatology of heat wave patterns from the simulated data indicates that different indices (intensity, frequency and duration) reveal different patterns. These patterns in turn reflect distinct features of the synoptic climatology of China. In the future, heat wave duration and frequency are projected to increase due to the effects of enhanced greenhouse gas concentration on future climate, which agrees well with previous studies. Projections of the AMT indicate that future heat waves in China could become more intense or more severe in the future. For instance, Díaz et al. (2002a,b) demonstrated that in Seville, Spain, the mortality rate increased by up to $51 \%$ above the average in the over 75 yr old age group for each degree Celsius beyond $41.8^{\circ} \mathrm{C}$ (the threshold for their definition of extremely hot days). Even though no similar study has ever been made until now in China, we are still aware of the potential dangers of heat waves.

Having analyzed the spatial distribution of the change in heat waves (intensity, frequency and duration), we tried to gain insight into the mechanisms responsible for this increase. In doing this, the simulated changes in temperature, precipitation, soil moisture (SM), sensible heat flux (H) and latent heat flux (LE) were carefully analyzed. To better understand heat wave increases and their distinct geographical patterns, we also examined the spatial distribution of the change in SM and $500 \mathrm{hPa}$ height anomalies.

We first tried to understand the links with changes in temperature, precipitation and SM and then explored the underling mechanisms responsible for heat wave increase. For this purpose, we selected spatially averaged changes in western Northwest China as examples of future increases in heat wave frequency (Fig. 4) across the whole of China (Fig. 1). The simulated $\mathrm{H}$ and LE are shown in Fig. 7, as are the changes in tem- 

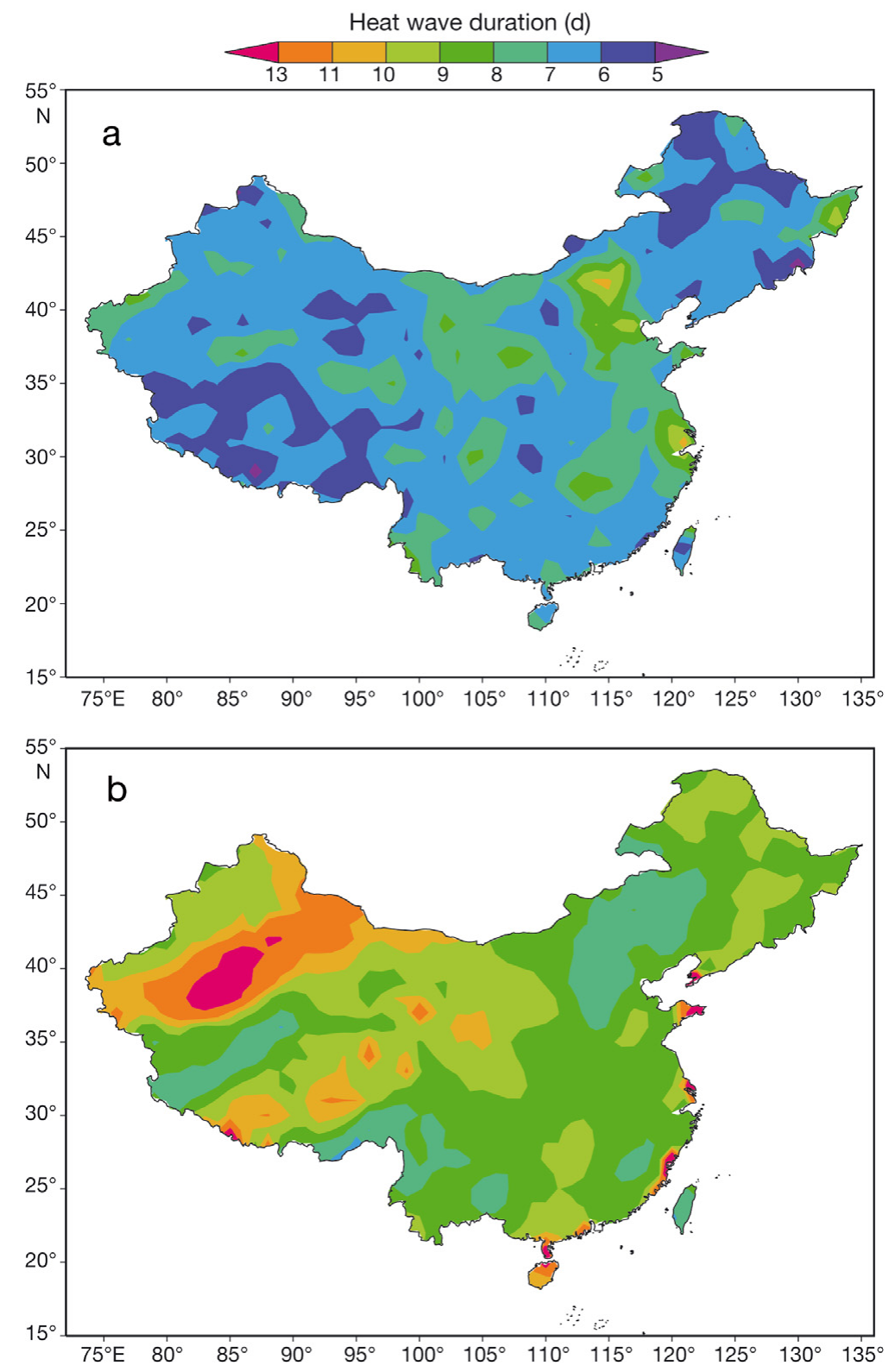

Fig. 5. Simulated spatial distribution of heat wave duration for (a) present (1961-1990) and (b) future (2071-2100) climate

perature, changes in precipitation and SM (which affects the partitioning between $\mathrm{H}$ and LE). We have mainly discussed the changes in western Northwest China, and used the whole of China as a reference. The temperature change shows an obvious peak in warming in late summer, and greater warming in western Northwest China than in the rest of China. The simulated mean precipitation in China shows a general increase, but decreases in summer in western Northwest China. There appears to be a decrease in SM that begins slowly in spring and becomes especially pronounced in summer and early autumn, aris- ing from reduced summer precipitation as well as increased winter and spring evaporation. LE increases in winter and spring, and then decreases dramatically in July and August due to the substantially reduced SM in late spring. The soil is much drier in late summer than in spring, which makes evaporation more sensitive to further reductions in SM. The decrease in LE leads to an increase in $\mathrm{H}$ that exhibits a noticeable peak in July-August, nearly in phase with the strongest warming. The simulated changes in China show qualitatively similar changes in western Northwest China. Across the whole of China, SM is reduced, summer LE is reduced and $\mathrm{H}$ is increased with a peak in summer. However, the magnitude of the changes is smaller in China as a whole than in western Northwest China. The differences in summer warming in different areas reflect, at least in part, different changes in SM and surface energy balance. The results for western Northwest China seem to provide a categorical example of increased heat waves.

SM shows significant geographical variation. For the SM anomaly (data not shown), there is a pronounced decrease in the western Northwest China, Northeast China and the eastern edge of the Tibetan Plateau, with a maximum in Northeast China. Note that the decrease in SM anomaly in these areas in the future climate is directly associated with more frequent and intense heat waves in those regions. Meanwhile, the mean base state change for the future climate shows $500 \mathrm{hPa}$ height anomalies of nearly +110 gpm over western Northwest and Northeast China, and about +65 gpm over South China at the end of the 21st century. The $500 \mathrm{hPa}$ height increases over western Northwest and Northeast China in the future climate are directly linked with the more intense and frequent heat waves in those regions. This highlights the importance of the anomalously dry soils and anticyclonic circulation anomalies and their close relation with heat waves. It also indicates the change in SM owing to changing precipitation and evapotranspiration, and that the associated nonlinear feedbacks with the surface energy balance, precipitation and circulation may lead to the change in heat waves, consistent with the previous studies over other regions (Rowell \& Jones 2006, Fischer et al. 2007, Lenderink et al. 2007, Vidale et al. 2007).

It should be noted that several of the processes influencing SM feedbacks operate at small scales, and need to be parameterized at the employed numerical resolu- 

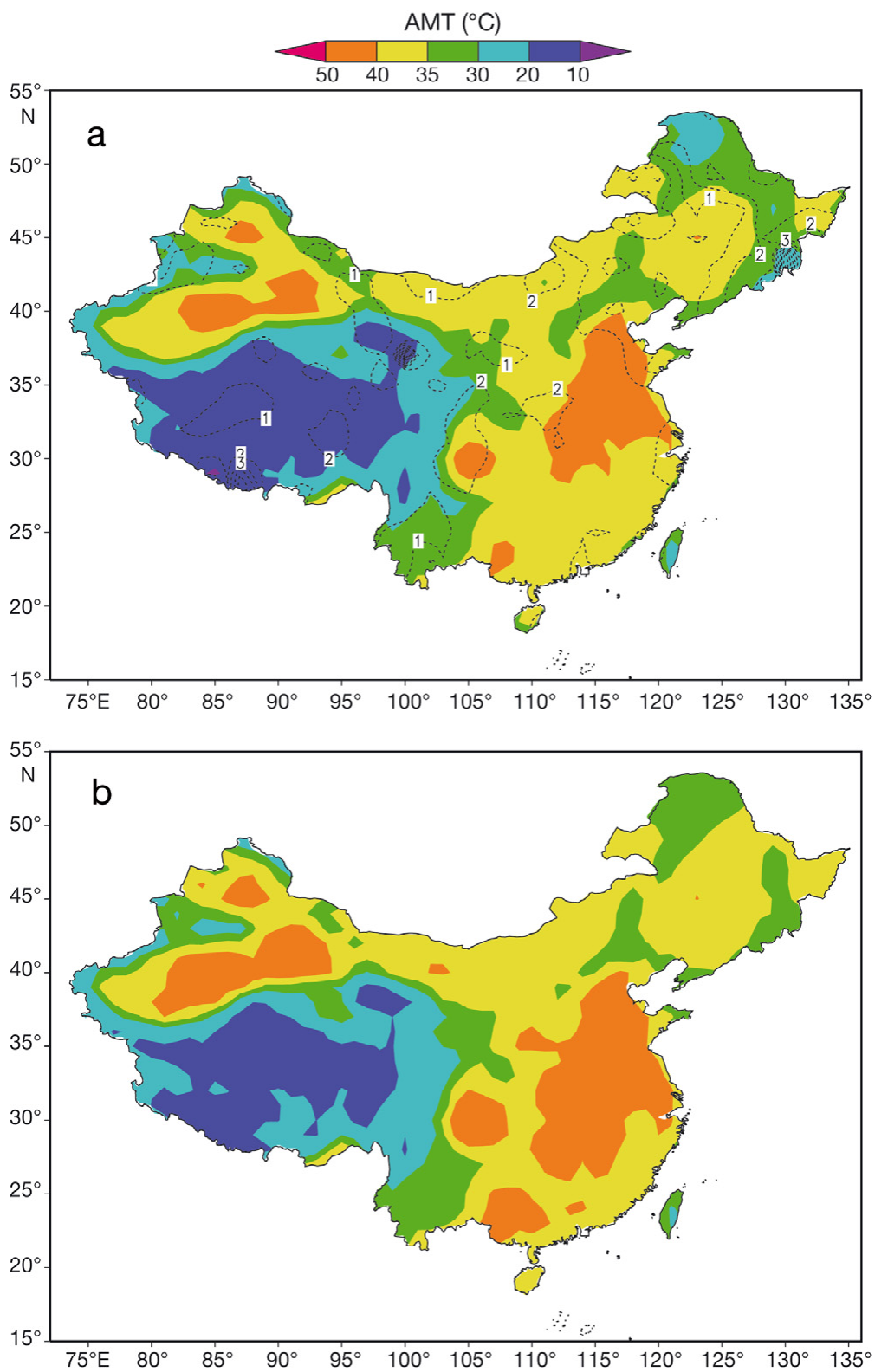

Fig. 6. Characteristics of the average maximum temperature (AMT, ${ }^{\circ} \mathrm{C}$ ) during heat waves for 2071-2100. (a) AMT anomaly with respect to AMT in 1961-1990. Bold contours display anomalies; colour shading shows AMT in 1961-1990. (b) Simulated AMT for 2071-2100

tion. Nevertheless, the parameterization of these processes might be uncertain. As a result, the simulated results may be model dependent and should be interpreted with caution. The main limitations of the present study have been the use of a single run of one model for one emissions scenario, which increases uncertainty in the regional change signal. Despite these uncertainties, the simulated extreme high tail of the probability density function of summer temperature and the circulation pattern during heat waves show a notable agreement with the validation data sets. These results could provide useful information for impact assessment as well as for a plausible interpretation of the future climate.

The definition of the heat wave used in the present study in a probability and statistics context has limitations in some areas with low mean temperatures. The Tibetan Plateau, for example, shows an increase in variability and mean temperature in response to the enhanced greenhouse gas levels in the future that may meet the criterion of a heat wave, but the 'heat wave' is not like the 2003 European heat wave. Because the present-day mean temperature in summer in these areas is below $10^{\circ} \mathrm{C}$, the average temperature during the heat waves may not appear high for the inhabitants in hot areas, but may nevertheless be high enough to have significant impacts on the local economy and ecosystems. The marked projected increase in heat waves in China underscores the need for more research regarding their human health and ecosystem impacts.

\section{CONCLUSIONS}

To validate the ability of the PRECIS model to simulate present extreme temperature events and to estimate possible future changes in China, we have analyzed the results of the PRECIS model for the present (1961-1990) and future (2071-2100) climate conditions. The simulated patterns of the extreme high tail of the probability density function of temperature for present-day China are similar to observations, but the simulation shows slightly higher temperatures in western Northwest, South and East China. The example of Wuhan validates the ability of the PRECIS model to simulate the atmospheric circulation patterns during the heat waves, and results show that the model can capture the anticyclonic circulation anomalies which are generally associated with heat waves.

The SRES A2 simulation in PRECIS up to 2100 shows that changes in the different heat wave indices (intensity, frequency and duration) follow different patterns. However, each heat wave index was found to increase, particularly those relating to duration, frequency and severity of heat waves. Thus the model projects more intense, longer and more frequent heat waves under continued greenhouse gas emissions. The results from PRECIS also indicate that western Northwest and Northeast China will likely become drier and warmer. 

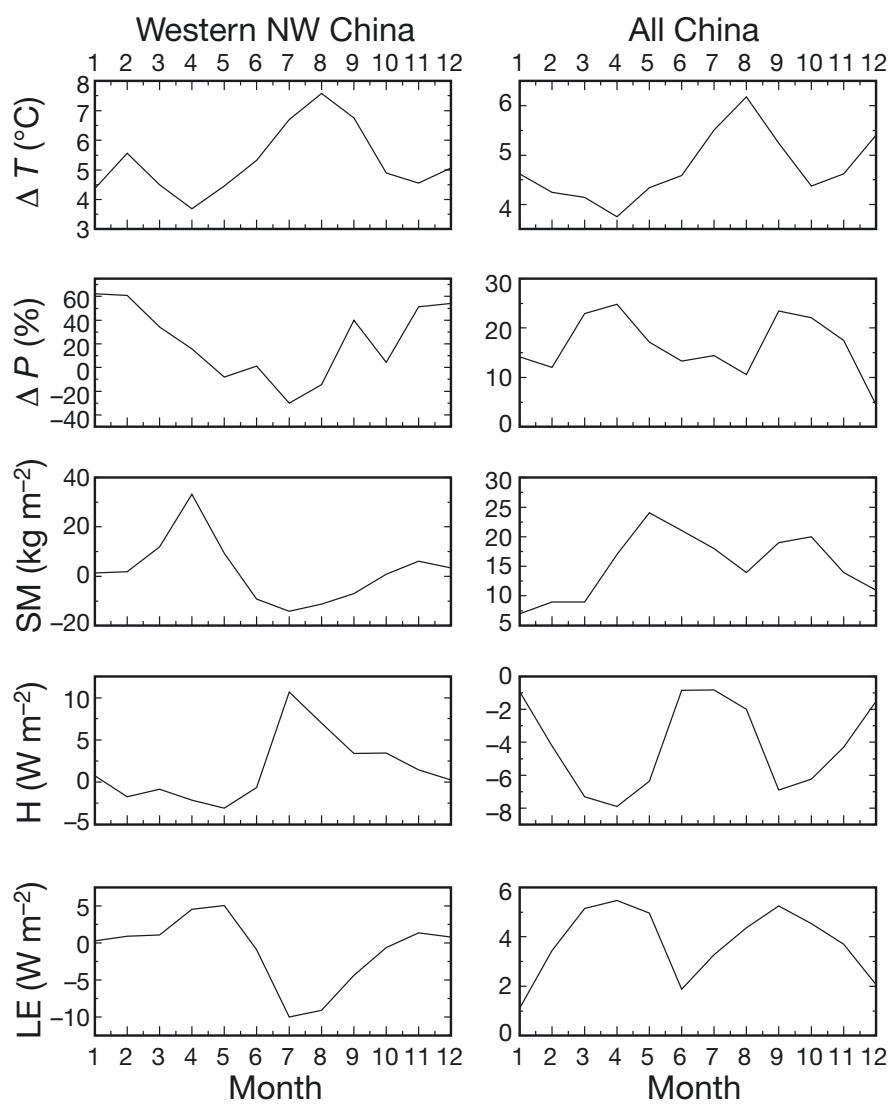

Fig. 7. Change in temperature $(T)$, change in precipitation $\left(P_{1}\right.$ percent of control run mean), soil moisture (SM), latent heat flux $(\mathrm{H})$ and sensible heat flux (LE) for western Northwest China and the whole of China

Acknowledgements. This research was supported by the National Science \& Technology Pillar Program (grant 2007 BAC03A02) and Impact Assessment System of Climate Change on grain production in China (grant GYHY 200806008). We would like to thank the Hadley Centre for providing the PRECIS model system, the Climatic Data Center, Meteorological Information Center, China Meteorological Administration for affording the observational data and reviewers of this manuscript for their useful comments and suggestions which have greatly improved the paper.

\section{LITERATURE CITED}

Alexander LV, Zhang X, Peterson TC, Caesar J and others (2006) Global observed changes in daily climate extremes of temperature and precipitation. J Geophys Res 111, D05109. doi:10.1029/2005JD006290

Beniston M (2004) The 2003 heat wave in Europe: a shape of things to come? An analysis based on Swiss climatological data and model simulations. Geophys Res Lett 31:L02202. doi:10.1029/2003GL018857

Bonsal BR, Zhang X, Vincent LA, Hogg WD (2001) Characteristics of daily and extreme temperatures over Canada. J Clim 14:1959-1976

Caesar J, Alexander L, Vose R (2006) Large-scale changes in observed daily maximum and minimum temperatures: creation and analysis of a new gridded data set. J Geophys Res 111:D05101. doi:10.1029/2005JD006280

- Clark RT, Brown SJ, Murphy JM (2006) Modeling Northern Hemisphere summer heat extreme changes and their uncertainties using a physics ensemble of climate sensitivity experiments. J Clim 19:4418-4435

> Díaz J, García R, de Castro FV, Hernández E, López C, Otero A (2002a) Effects of extremely hot days on people older than 65 years in Seville (Spain) from 1986 to 1997. Int J Biometeorol 46:145-149

Díaz J, Jordan A, Garcia R, Lopez C, Alberdi J, Hernandez E, Otero A (2002b) Heat waves in Madrid 1986-97: effects on the health of the elderly. Int Arch Occup Environ Health 75:163-170

> Fischer EM, Seneviratne SI, Vidale PL, Lüthi D, Schär C (2007) Soil moisture atmosphere interactions during the 2003 European summer heat wave. J Clim 20:5081-5099

Gao X, Zhao Z, Giorgi F (2002) Changes of extreme events in regional climate simulations over East Asia. Adv Atmos Sci 19:927-942

> Gruber S, Hoelzle M, Haeberli W (2004) Permafrost thaw and destabilization of Alpine rock walls in the hot summer of 2003. Geophys Res Lett 31:L13504. doi:10.1029/2004GL 020051

Huth R, Kyselý J, Pokorná L (2000) A GCM simulation of heat waves, dry spells, and their relationships to circulation. Clim Change 46:29-60

IPCC (2007) Climate change 2007: the physical science basis. Contribution of Working Group I to the Fourth Assessment Report of the Intergovernmental Panel on Climate Change. Cambridge University Press, Cambridge

Jones RG, Noguer M, Hassell D, Hudson D, Wilson S, Jenkins G, Mitchell J (2004) Generating high resolution climate change scenarios using PRECIS. Met Office Hadley Centre, Exeter

Karl TR, Knight RW (1997) The 1995 Chicago heat wave: How likely is a recurrence? Bull Am Meteorol Soc 78:1107-1119

Kovats RS, Koppe C (2005) Heat waves: past and future impacts. In: Ebi KL, Smith JB, Burton I (eds) Integration of public health with adaptation to climate change: lessons learned and new directions. Taylor \& Francis, London

Kovats RS, Hajat S, Wilkinson P (2004) Contrasting patterns of mortality and hospital admissions during hot weather and heat waves in Greater London, UK. Occup Environ Med 61:893-898

Kunkel KE, Changnon SA, Reinke BC, Arritt RW (1996) The July 1995 heat wave in the Midwest: a climatic perspective and critical weather factors. Bull Am Meteorol Soc 77 : $1507-1518$

Lenderink G, van Ulden A, van den Hurk B, van Meijgaard E (2007) Summertime inter-annual temperature variability in an ensemble of regional model simulations: analysis of the surface energy budget. Clim Change 81:233-247

Lin E, Xiong W, Ju H, Xu YL, Li YE, Bai LP, Xie LY (2005) Climate change impacts on crop yield and quality with $\mathrm{CO}_{2}$ fertilization in China. Philos Trans R Soc Lond B 360: $2149-2154$

Meehl GA, Tebaldi C (2004) More intense, more frequent, and longer lasting heat waves in the 21st century. Science 305:994-997

Palecki MA, Changnon SA, Kunkel KE (2001) The nature and impacts of the July 1999 heat wave in the Midwestern United States: learning from the lessons of 1995. Bull Am Meteorol Soc 82:1353-1368

Ren G, Xu M, Tang G, Zhang L and others (2003) Climate changes of the past 100 years in China. Clim Newsl 4:4-5 
Rowell D (2005) A scenario of European climate change for the late twenty-first century: seasonal means and interannual variability. Clim Dyn 25:837-849

Rowell D, Jones R (2006) Causes and uncertainty of future summer drying over Europe. Clim Dyn 27:281-299

Schär C, Jendritzky G (2004) Climate change: hot news from summer 2003. Nature 432:559-560

Schär C, Vidale PL, Luthi D, Frei C, Haberli C, Liniger MA, Appenzeller C (2004) The role of increasing temperature variability in European summer heat waves. Nature 427: 332-336

Stott PA, Stone DA, Allen MR (2004) Human contribution to the European heatwave of 2003. Nature 432:610-614

Tebaldi C, Hayhoe K, Arblaster J, Meehl G (2006) Going to the extremes: an intercomparison of model-simulated historical and future changes in extreme events. Clim Change 79: $185-211$

> Valleron AJ, Boumendil A (2004) Epidemiology and heat waves: analysis of the 2003 episode in France. C R Biol 327: 1125-1141

Vidale P, Lüthi D, Wegmann R, Schär C (2007) European summer climate variability in a heterogeneous multi-model ensemble. Clim Change 81:209-232

Xoplaki E, Gonzalez-Rouco JF, Luterbacher J, Wanner H (2003) Mediterranean summer air temperature variability and its connection to the large-scale atmospheric circulation and SSTs. Clim Dyn 20:723-739

Editorial responsibility: Peter Gleckler, Livermore, California, USA
Xu Y, Huang X, Zhang Y, Lin W, Lin E (2006a) Statistical analyses of climate change scenarios over China in the 21st century. Adv Clim Change Res 2:50-53

Xu Y, Zhang Y, Lin E, Lin W and others (2006b) Analyses on the climate change responses over China under SRES B2 scenario using PRECIS. Chin Sci Bull 51:2260-2267

Xu Y, Gao X, Shen Y, Xu C, Ying S, Giorgi F (2009) A daily temperature dataset over China and its application in validating a RCM simulation. Adv Atmos Sci 26:763-772

Yan Z, Jones PD, Davies TD, Moberg A and others (2002) Trends of extreme temperatures in Europe and China based on daily observations. Clim Change 53:355-392

> Zhai P, Pan X (2003) Trend in temperature extremes during 1951-1999 in China. Geophys Res Lett 30:1913. doi:10. 1029/2003GL018004

> Zhang X, Hegerl G, Zwiers FW, Kenyon J (2005) Avoiding inhomogeneity in percentile-based indices of temperature extremes. J Clim 18:1641-1651

Zhang Y, Xu Y, Dong W, Cao L, Sparrow M (2006) A future climate scenario of regional changes in extreme climate events over China using the PRECIS climate model. Geophys Res Lett 33:L24702. doi:10.1029/2006GL027229

Zhang Y, Xu Y, Dong W, Cao L (2007) A preliminary analysis of distribution characteristics of maximum and minimum temperature and diurnal temperature ranges over China under SRES B2 scenario. Chin J Geophys 50: $714-723$

Submitted: May 22, 2009; Accepted: March 25, 2010 Proofs received from author(s): May 27, 2010 